\title{
Origami Blossom
}

Jung Eun Lee

Virginia Tech

Keywords: Origami clothing design, rose, textile design

Origami has inspired some fashion designers such as Issey Miyake and Charles James. For example, Issey Miyake creates garments by using permanently pleated polyester fabric, which was inspired by the traditional form of paper lanterns. The purpose of this clothing design is to create an elegant garment with elements of an origami rose. First, the basic under dress was created using heavy tulle material to create the shape of the dress. Then, each piece of fabric was folded and pressed with a hot iron. This dress used polyester satin fabric to provide an elegant look and to hold its shape. Each folded fabric piece was sewn and assembled together by layering fabrics which creates the origami rose surface. This design represents a cohesive theme of an origami rose throughout the dress and presents an elegant look. This design is innovative in terms of developing a unique textile by layering fabrics and incorporating an origami rose to fashion.
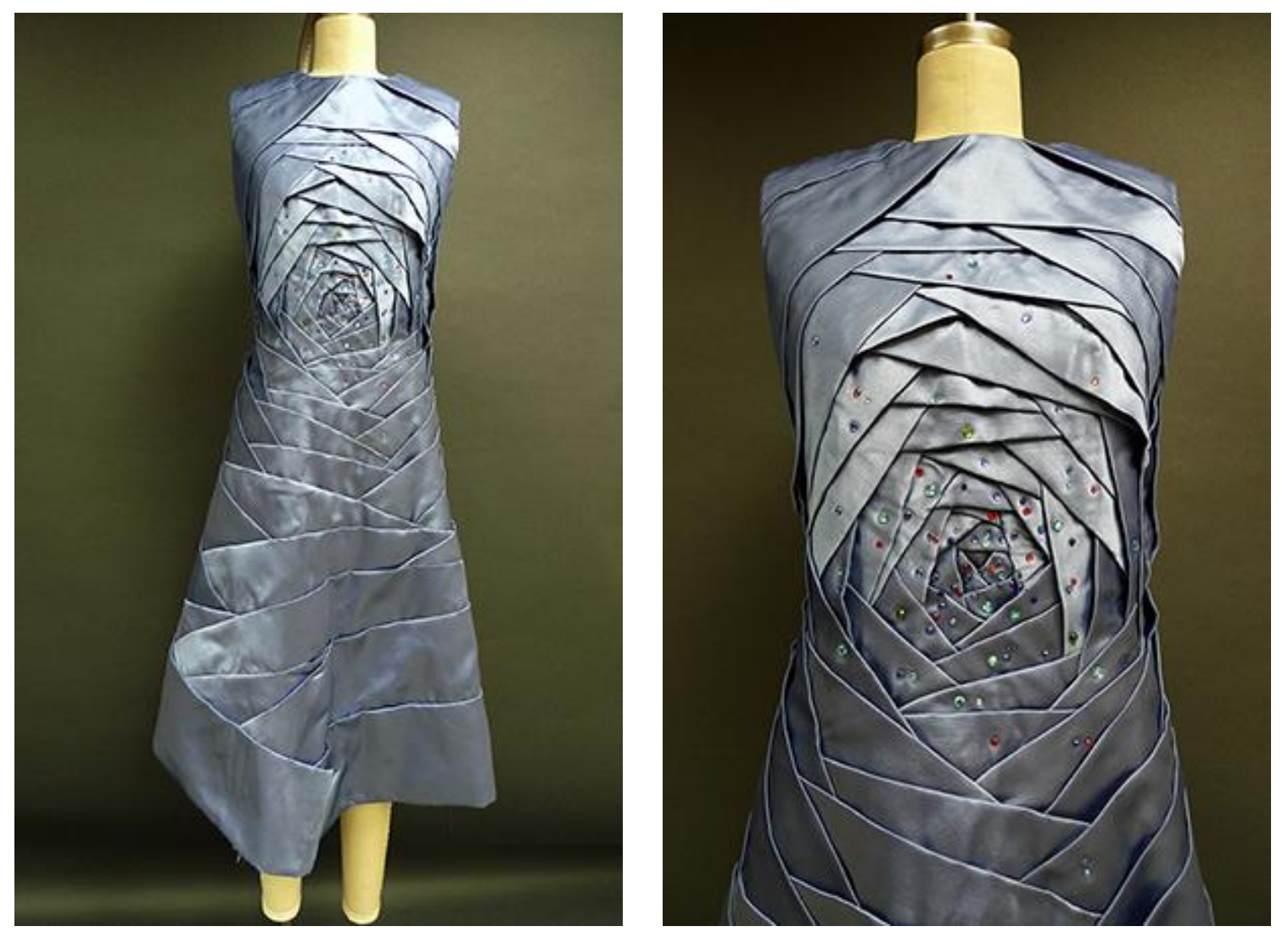